Zheng-Nian Ding MD, Keizo Shibata MD, Ken Yamamoto MD, Tsutomu Kobayashi MD, Seiitsu Murakami MD

\title{
Equipment
}

\section{Decreased circulation time in the upper limb reduces the lag time of the finger pulse oximeter response}

To observe the influence of circulatory changes on the lag time of the pulse oximeter response, eight healthy patients scheduled for hand surgery were studied. After breath holding, the patients took a breath of oxygen and the time to an increase in $\mathrm{SpO}_{2}$ was measured before and after axillary brachial plexus block. It was found that the lag time with finger probe decreased from $28.6 \pm$ 7.1 sec to $15.8 \pm 1.1 \mathrm{sec}$ (mean $\pm S D$ ) following brachial block $(P<0.01)$. There was no change in arterial blood pressure. The results suggest that the lag time of the finger pulse oximeter response is primarily determined by blood flow.

Afin d'observer l'influence des changements circulatoires surle temps de réponse du saturomètre, huit patients en santé devant subir une chirurgie de la main ont été étudiés. Après avoir retenu leur respiration, les patients ont pris une respiration sous oxygène et le temps d'attente jusqu'à l'observation d'une augmentation de la $\mathrm{SpO}_{2}$ a été mesuré avant et après le bloc du plexus axillaire. Il a été noté que le temps de réponse avec la pièce digitale diminuait $(P<0,01)$ de $28,6 \pm 7,1$ sec à $15,8 \pm$ $I, I$ sec (moyenne \pm ET) après le bloc axillaire. Il n'y avait aucun changement de la tension artérielle. Ces résultats

\section{Key words}

ANAESTHETIC TECHNIQUES: axillary brachial plexus block;

EQUIPMENT: pulse oximeter;

PHYSICS: flow, velocity.

From the Department of Anesthesiology and Intensive Care Medicine, School of Medicine, Kanazawa University, Kanazawa 920, Japan.

Address correspondence to: Dr. Zheng-Nian Ding, Department of Anesthesiology and Intensive Carc Medicine, School of Medicine, Kanazawa University, 13-1 Takara-machi, Kanazawa 920 Japan.

Accepted for publication 12th August, 1991. suggèrent que le temps de réponse de la pièce digitale du saturomètre est principalement déterminé par le débit sanguin.

Pulse oximeters have been used widely to monitor blood oxygenation continuously, non-invasively, and accurately during anaesthesia. ${ }^{1,2}$ When the inspired oxygen concentration is changed, the oxygen saturation measured with a pulse oximeter will, after a time delay, also change. This delay is called the lag time or detection time. ${ }^{3-7}$ Previous work has shown that the lag time of a finger probe pulse oximeter response (finger lag time, FLT) is prolonged by cold-induced vasoconstriction or by inflating a sphygmomanometer cuff applied to the upper arm to $40 \mathrm{mmHg}$; ${ }^{6,7}$ both procedures decrease the blood flow in the upper limb. These findings suggested that the circulation time, which is determined by the blood flow and systemic arterial pressure $^{8-14}$ is a primary determinant of FLT. To examine this hypothesis, we measured the FLT before and after axillary brachial plexus block $(\mathrm{AB})$ which increases the blood flow in the upper limb ${ }^{15,16}$ without changing systemic arterial pressure.

\section{Methods}

After obtaining the approval of the Ethics Committee as well as the informed consent from eight outpatients scheduled to undergo hand surgery (ulnar neurolysis, finger tumour excision, plasty after dermal-fat graft etc.) under continuous axillary brachial plexus block (AB), ${ }^{17}$ we studied the FLT of these patients. No premedication was given. All patients were ASA physical status I-II and none had any cardiopulmonary disease. Thirty millilitres of $1.5 \%$ mepivacaine without epinephrine were used to induce the initial block after the placement of a $5 \mathrm{~cm} 23$ gauge teflon intravenous catheter in the axillary perivascular sheath.

To measure the FLT, a PULSEMATE instrument (BX- 
TABLE Ranges (mean $\pm S D$ ) of age. weight and height, and the sex distribution of the patients

\begin{tabular}{llccc}
\hline$n$ & $\operatorname{Sex}(M / F)$ & Age $(\mathrm{yr})$ & Weight $(\mathrm{kg})$ & Height $(\mathrm{cm})$ \\
\hline 8 & $7 / 1$ & $21-71$ & $48-80$ & $148-193$ \\
& & $(44.8 \pm 15.7)$ & $(64 \pm 13)$ & $(166 \pm 14.5)$ \\
\hline
\end{tabular}

5, Nippon Colin, Japan), consisting of a pulse oximeter and an automatic sphygmomanometer, was used. The patient was asked to lie in the supine position and the limb was placed at the same level as the trunk to avoid gravitational and positional affects. ${ }^{18}$ The pulse oximeter probe was attached to the thumb, index or middle finger on the side to be operated upon. When a stable reading on the pulse oximeter was obtained, the subject was asked to breathhold for as long as possible at the end of a forced expiration, and then to take a deep inspiration of $100 \%$ oxygen. The time from the beginning of the oxygen inspiration to the time when the reading on the pulse oximeter began to increase was taken as the FLT. The measurements were performed before $\mathrm{AB}$ and $20 \mathrm{~min}$ after the initial dose of local anaesthetic for the AB. The patient was asked not to move the hand to which the probe was attached.

The blood pressure was measured in the opposite arm simultaneously.

To insure the repeatability of this technique, the FLT was also measured twice within five-minute intervals in volunteers $(n=10)$ under the same conditions.

All procedures were performed in an air-conditioned operating room with a constant temperature of $23-25^{\circ} \mathrm{C}$.

Student's t test was used for statistical comparison. $P<$ 0.05 was considered significant.

\section{Results}

The patients' characteristics are shown in the Table. In all patients the operations were performed on the right hand. Axillary block was almost complete in all patients. The oxygen saturation measurement at rest was $96-98 \%$. It began to decrease as the breath holding continued and continued to decrease after the inspiration of oxygen. After a stable phase, the reading on pulse oximeter increased abruptly to $98-100 \%$. The lowest saturations varied from $89 \%$ to $94 \%$. The FLT was reduced from $28.6 \pm 7.1 \mathrm{sec}$ (mean $\pm \mathrm{SD})$ to $15.8 \pm 1.1 \mathrm{sec}$ after the $\mathrm{AB}(P<0.01)$ (Figure). The mean arterial pressure did not change.

In volunteers, the FLT was $25.2 \pm 3.2 \mathrm{sec}$ and the difference between duplicate measurements under the same conditions was $1.1 \pm 0.6 \mathrm{sec}$.

\section{Discussion}

In this study AB did not change mean arterial pressure and was satisfactory for the operations in almost all patients.

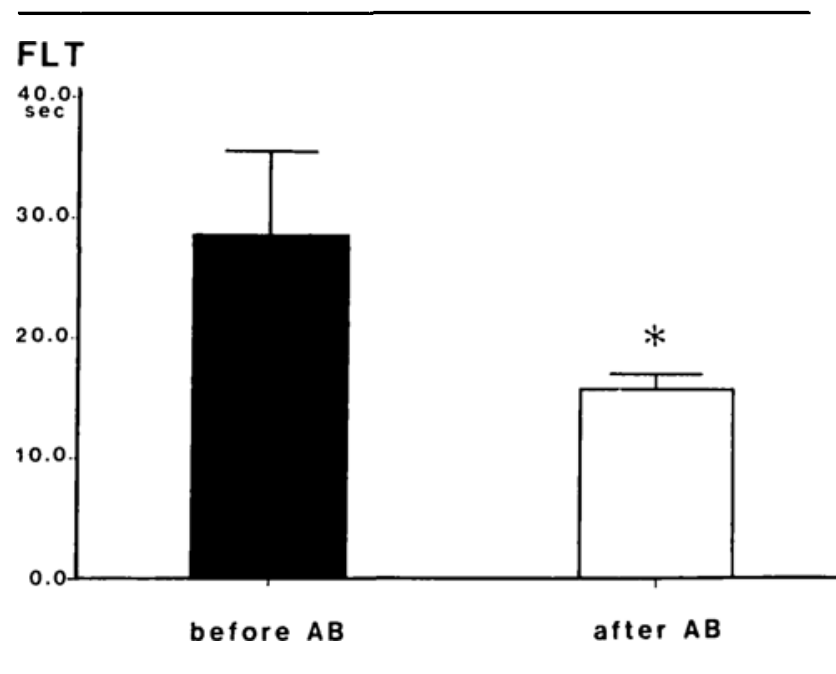

FIGURE The finger lag time (FLT) before and after axillary brachial plexus block $(\mathrm{AB}) .{ }^{*}$ Significantly $(P<0.01)$ different from the FLT bcfore AB.

As expected, the FLT was reduced by $40 \%$ after AB. The FLT was measured while breathing oxygen after breathholding. This is simpler than using nitrogen inspiration. ${ }^{3-7}$ Breath holding at the end of a forced expiration results in a decrease in oxygen saturation as the residual volume in the lung decreases. The small difference between duplicate measurements under the same conditions in volunteers suggests this is a reliable technique to measure FLT.

Axillary block increases the blood flow in the upper limb. ${ }^{15,16}$ In conditions when the perfusion pressure does not change, ${ }^{13,14}$ the increased blood flow will result in an increase in blood flow velocity or a decrease in circulation time. ${ }^{8-12}$ In this study, the mean arterial pressure did not change and the axillary block resulted in almost complete anaesthesia.

During the resaturation process, the oxygen saturation shown on the pulse oximeter began to increase only as the more highly saturated blood passed through the finger. The lag time to pulse oximeter response, therefore, can be considered to be made up of the following components: (1) inspiration and diffusion time: the time required for the distribution of inspired oxygen into the alveoli and that for the diffusion of oxygen molecules from the alveoli to the erythrocytes in the pulmonary capillaries; (2) circulation time: the time taken for the transportation of highly saturated blood from the pulmonary capillaries to the arteriole in the finger where the pulse oximeter attached to; (3) instrument response time: the time for sampling and averaging by the pulse oximeter. The inspiration time is determined by airway resistance and the performance of the respiratory muscles, and the diffusion time is determined by the condition of the alveolar-capillary tissue interface. These should not be affected by AB: the former 
is about one second ${ }^{19}$ and the latter is negligible in a healthy person. The instrument response time for the pulse oximeter employed in the present study is five seconds. Thus the decrease in FLT after AB was caused by the decreased circulation time.

The pulse oximeter has been used to assess collateral arterial flow $\mathrm{w}^{20}$ and to monitor the vascular conditions in upper extremity replantation surgery. ${ }^{21}$ Also, the lag time has been used as an index to evaluate the pulse oximeter. ${ }^{3-7}$ However, the relation between the lag time and the circulation time has not been clearly stated. Obviously, any cardiovascular disturbance which affects the circulation time will also affect the FLT. Thus, coldinduced vasoconstriction and sphygmomanometer cuff inflation must have increased the circulation time. ${ }^{6-7}$ The FLT variation among the patients before the $\mathrm{AB}(\mathrm{SD}=$ $7.1 \mathrm{sec}$ ) may have been caused by circulatory abnormalities. One patient, who complained of coldness of the injured hand after a dermal-fat graft operation for a degloved injury, showed the longest baseline FLT (39.1 sec). The FLT variation after AB (SD = $1.1 \mathrm{sec})$ decreased, which may partially be explained by the reduction of circulation time.

Our results suggest that the lag time of the finger pulse oximeter response is not primarily determined by the pulse oximeter itself, but by the circulation time. When the circulation time decreases, the lag time to pulse oximeter response will be reduced and, conversely, an increased circulation time will result in a prolonged lag time.

\section{References}

1 Yelderman $M$, New $W J r$. Evaluation of pulse oximetry. Anesthesiology 1983; 59: 349-52.

2 Tremper KK, Barker SJ. Pulse oximetry. Ancsthesiology 1989; 70: 98-108.

3 Severinghaus $J W$, Naifeh $K H$. Accuracy of response of six pulse oximeters to profound hypoxia. Anesthesiology 1987; 67: 551-8.

4 Rebuck AS, P FCC, Chapman KR, D'Urzo A, PhE B. The accuracy and response characteristics of a simplified ear oximcter. Chest 1983; 83: 860-4.

5 Kagle DM, Alexender CM, Berko RS, Giuffre M. Gross $J B$. Evaluation of the Ohemeda 3700 pulse oximeter: steady-state and transient response characteristics. Anesthesiology 1987; 66: 375-80.

6 Wilkins CJ, Moores M, Hanning CD. Comparison of pulse oximeters: effects of vasoconstriction and venous engorgement. Bri J Anaesth 1989; 62: 439-44.

7 Langton JA, Lassey $D$, Hanning $C D$. Comparison of four pulse oximeters: effects of venous occlusion and coldinduced peripheral vasoconstriction. Br J Anaesth 1990; 65: $245-7$.
8 Shionoya S, Matsubara J, Hirai M et al. Measurement of blood pressurc, blood flow and blood flow velocity in arterial reconstruction of the lower extremity. Angiology 1983: 34: 244-55.

9 Riva CE, Grunwald JE, Sinclair SH, Petring BL. Blood velocity and volumetric flow rate in human retinal vessels. Invest Ophthamol Vis Sci 1985; 26: 1124-32.

10 Silverman NR, Rosen L. Arterial blood flow measurement: assessment of velocity estimation methods. Invest Radiol 1977: 12: 319-24.

11 Stein PD, Badeer HS, Schuttle WH. Zencka AE, Omaha. Velocity of coronary sinus blood flow as an indicator of coronary arterial flow. Am Heart J 1970; 80: 202-8.

12 Cronquist S, Greitz, T. Cerebral circulation time and cerebral blood flow. Acta Radiol Diag 1969; 8: 296-304.

13 David Spence J. Effects of antihypertensive agents on blood velocity: implication for atherogenesis. Can Med Assoc J 1982; 15: 721-4.

14 David Spense J, Melmon KL. Effects of antihypertensive drugs on blood velocity in rhesus monkeys. Stroke 1977; 8: 589-94.

15 Lofstrom JB, Lloyd JW, Cousins MJ. Sympathetic neural blockade of upper and lower extremity. In: Cousins MJ, Bridenbaugh PO (Eds.). Neural Blockade. Clinical Anesthesia and Management of Pain. Toronto: Philadephia, 1980; 355-8.

16 Zen $M$, Tryba $M$, Horch $C$. Sympathicusblockade nach Plexusanaesthesie. Reg Anaesth 1986; 9: 84-7.

17 Sada T, Kobayashi T, Murakami S. Continuous axillary brachial plexus block. Can Anaesth Soc J 1983; 30: 201-5.

18 Blick EF, Stein PD. A review of second-order effects on Poiseuille's equation for application to blood and other viscous fluids. Med Res Eng 1976; 11: 27-31.

19 Agostoni E, Fenn WO. Velocity of muscle shorting as a limiting factor in respiratory air flow. J Appl Physiol 1960; 15: 349-53.

20 Nowak GS, Moorthy SS, McNiece WL. Use of pulse oximetry for assessment of collateral arterial flow. Anesthesiology 1986; 64: 527.

21 Graham B, Paulus DA, Caffee $H H$. Pulse oximetry for vascular monitoring in upper extremity replantation surgery. J Hand Surg (Am) 1986; 11 A: 687-92. 